OPEN ACCESS

Edited by:

Mark Slevin,

Manchester Metropolitan University, United Kingdom

Reviewed by:

Toshiyuki Murai,

Osaka University, Japan

Maryna Skok,

Palladin Institute of Biochemistry

(NAS Ukraine), Ukraine

*Correspondence:

Shang-Rong Ji

jsr@lzu.edu.cn;

Yi Wu

wuy@/zu.edu.cn

Specialty section: This article was submitted to Inflammation,

a section of the journal

Frontiers in Immunology

Received: 06 January 2018 Accepted: 27 February 2018

Published: 12 March 2018

Citation:

Zhang L, Li H-Y, Li W, Shen Z-Y, Wang $Y$-D, Ji S-R and Wu Y (2018)

An ELISA Assay for Quantifying Monomeric C-Reactive Protein

in Plasma.

Front. Immunol. 9:511. doi: 10.3389/fimmu.2018.00511

\section{An ELISA Assay for Quantifying Monomeric C-Reactive Protein in Plasma}

\author{
Lin Zhang ${ }^{1}$, Hai-Yun Li', Wei Li', Zhi-Yuan Shen'², Yin-Di Wang ${ }^{3}$, Shang-Rong Ji * \\ and $Y i W^{1 *}$
}

${ }^{1}$ MOE Key Laboratory of Environment and Genes Related to Diseases, School of Basic Medical Sciences, Xi'an Jiaotong University, Xi'an, China, ${ }^{2}$ MOE Key Laboratory of Cell Activities and Stress Adaptations, School of Life Sciences, Lanzhou University, Lanzhou, China, ${ }^{3}$ Ultrasound Department, The Second Hospital of Lanzhou University, Lanzhou, China

Native C-reactive protein (nCRP) is a non-specific marker of inflammation being claimed as a bystander in several chronic disorders. Accumulating evidence indicates that $\mathrm{nCRP}$ dissociates to and acts primarily as the monomeric conformation (mCRP) at inflammatory loci. This suggests that mCRP may be a superior disease marker with improved specificity and clear causality to the underlying pathogenesis. However, the lack of a feasible assay to quantify mCRP in clinical samples precludes the assessment of that suggestion. Here we report the development of a sandwich ELISA assay for quantification of plasma mCRP using commercially available reagents. Our assay is reproducible and highly conformation-specific showing a reliable detection limit of $1 \mathrm{ng} / \mathrm{mL}$. We further show that MCRP appears to be a better marker than nCRP in several skin-related autoimmune disorders. This assay thus provides a useful tool to examine the clinical significance and utility of mCRP.

\footnotetext{
Keywords: inflammation, autoimmune diseases, urticaria, psoriasis, C-reactive protein, monomeric C-reactive protein
}

\section{INTRODUCTION}

Native C-reactive protein (nCRP) is a major human acute phase reactant that responds to tissue damage or infection by rapidly increasing its blood concentrations $(1,2)$. It thus has been widely used as a non-specific marker of inflammation in clinical practice. Moreover, a minor increase in the circulating level of nCRP, originally considered as non-pathological, is found to be associated with the risk and prognosis of several chronic inflammatory disorders, including cancer (3) and cardiovascular disease (4). However, those associations are usually moderate and are shown to be non-causal by large-scale genetic studies $(5,6)$. Therefore, it appears plausible that nCRP may simply be a bystander in these diseases $(3,4)$.

Native C-reactive protein is composed of five identical subunits that are induced to dissociate at inflammatory loci (7-11) upon encountering damaged membranes (12-21), amyloid aggregates (22), neutrophil extracellular traps (23), or acidic pH (24). The dissociated conformation is termed as monomeric CRP (mCRP) and could be the major actor in local inflammation (7-11). This argues that $\mathrm{mCRP}$ may be a marker more specific to the underlying pathological processes. Indeed, circulating or microparticle-bound $\mathrm{mCRP}$ has been shown to be a better diagnostic index than nCRP in myocardial infarction $(20,25)$ and peripheral artery disease $(26)$. However, the homemade assays used in these studies prohibit broad evaluation of the above argument. To clear that hurdle, here we 
develop a highly specific ELISA assay to measure plasma levels of mCRP based on commercially available reagents.

\section{MATERIALS AND METHODS}

\section{Reagents}

Native C-reactive protein (purity $>$ 97\%) purified from human ascites was purchased from the BindingSite (Birmingham, UK; catalog number: BP300.X; lot number: 361639 and 404353) and repurified with p-Aminophenyl Phosphoryl Choline Agarose (Thermo Fisher Scientific, Rockford, IL, USA; catalog number: 20307). mCRP was prepared by treatment of nCRP with 8-M urea-EDTA (27) or by recombinant expression and purification $(28,29)$. Our assay worked well for both forms of mCRP. Proteins were dialyzed to remove $\mathrm{NaN}_{3}$, and passed through Detoxi-Gel Columns (Thermo Fisher Scientific, Rockford, IL, USA; catalog number: 20344) to remove endotoxin when necessary. Mouse antihuman CRP Abs 1D6 and 3H12 were generated as described $(30,31)$.

\section{ELISA Assay Quantifying nCRP}

The sheep antihuman CRP polyclonal antibody (BindingSite; catalog number: PC044; lot number: 352325, 076682) was immobilized onto microtiter wells (Corning, NY, USA; catalog number: 42592; lot number: 10917007) at $2.5 \mu \mathrm{g} / \mathrm{mL}$ in coating buffer (10-mM sodium carbonate/bicarbonate, $\mathrm{pH}$ 9.6) overnight at $4^{\circ} \mathrm{C}$. All the following steps were conducted at $37^{\circ} \mathrm{C}$. Wells were washed with TBS $(10-\mathrm{mM}$ Tris, $140-\mathrm{mM}$ $\mathrm{NaCl}, 2-\mathrm{mM} \mathrm{Ca}, \mathrm{pH} 7.4$ ) containing $0.02 \% \mathrm{NP}-40$, and then blocked with $1 \%$ BSA in TBS (blocking buffer). Samples diluted in blocking buffer were added into wells for $1 \mathrm{~h}$. Captured CRP was detected with $1 \mathrm{D} 6 \mathrm{mAb}$ (1:300 in blocking buffer) that specifically recognizes the native conformation and an HRPlabeled goat anti-mouse IgG $(\mathrm{H}+\mathrm{L})$ (1:20,000 in blocking buffer) (Jackson ImmunoResearch, West Grove, PA; catalog number: 115-035-003; lot number: 125229). Wells were developed with TMB (Sigma-Aldrich; catalog number: T2885; lot number: WXBC2414V) and stopped with 1- $\mathrm{M} \mathrm{H}_{2} \mathrm{SO}_{4}$. OD570 and OD450 $\mathrm{nm}$ were measured with a microplate reader. The OD value of each sample was calculated as OD450-OD570 nm. $100-\mu \mathrm{L}$ volume was used at all incubation steps, while $300-\mu \mathrm{L}$ volume was used for washing after each incubation step.

\section{ELISA Assay Quantifying mCRP}

The mouse antihuman CRP mAb CRP-8 (Sigma-Aldrich, St. Louis, MO, USA; catalog number: C1688; lot number: 025M4863V) was immobilized onto microtiter wells (Thermo Fisher Scientific; catalog number: 468667, 442404; lot number: 148860, 148034; Corning, NY, USA; catalog number: 42592; lot number: 10917007$)$ at $1: 1,000$ in coating buffer $(10-\mathrm{mM}$ sodium carbonate/bicarbonate, $\mathrm{pH} 9.6$ ) overnight at $4^{\circ} \mathrm{C}$. The performance of the assay was comparable regardless of the type of microtiter well used. $3 \mathrm{H} 12$ (1:200) was also immobilized as the capture antibody to compare its performance with that of CRP-8 as shown in Figure 1B. All the following steps were conducted at $37^{\circ} \mathrm{C}$. Wells were washed with TBS containing $0.02 \%$ NP-40, and then blocked with $1 \%$ BSA in TBS (blocking buffer). TBS was made of 10-mM Trizma base (Sigma; catalog number: V900483), $140-\mathrm{mM} \mathrm{NaCl}$ (Amresco, Solon, OH, USA; catalog number: X190), and 2- $\mathrm{mM} \mathrm{CaCl}_{2}$ (Sinopharm, Shanghai; catalog number: 10005861) in ultrapure water (>18.2 M $\Omega . c m$ ) with $\mathrm{pH}$ adjusted to 7.4. Samples diluted in blocking buffer were added into wells for $1 \mathrm{~h}$. Captured mCRP was detected with a sheep antihuman CRP polyclonal antibody (1:2,000 in blocking buffer) (BindingSite; catalog number: PC044; lot number: 352325, 076682) and an HRP-labeled donkey anti-sheep IgG $(\mathrm{H}+\mathrm{L})$ from Abcam $(1: 10,000$ in blocking buffer) (Cambridge, UK; catalog number: ab6900; lot number: GR272029-6) or from Abbkine (1:20,000 in blocking buffer) (Wuhan, China; catalog number: A21060-1; lot number: ATQMA0601, ATQJN0701). Wells were developed with TMB and stopped with $1-\mathrm{M} \mathrm{H}_{2} \mathrm{SO}_{4}$. OD570 and OD450 $\mathrm{nm}$ were measured with a microplate reader. The OD value of each sample was calculated as OD450-OD570 nm. 100- $\mu \mathrm{L}$
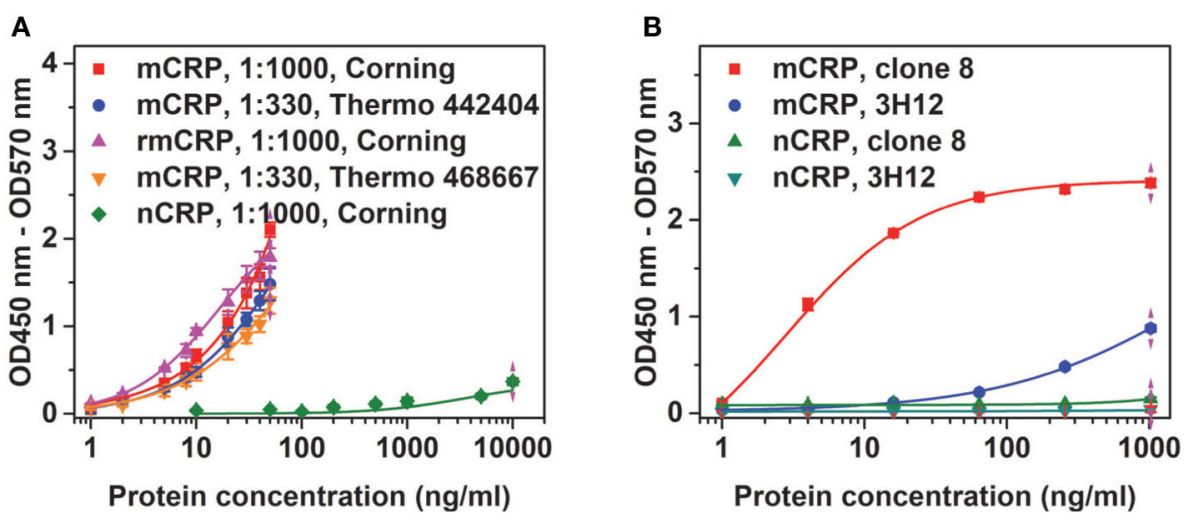

FIGURE 1 | Conformation specificity of the assay. (A) Native C-reactive protein (nCRP), monomeric CRP (mCRP), or recombinant mCRP (rmCRP) at the indicated concentrations were added to the indicated wells coated with 1:1,000 or 1:330 CRP-8 mAb, and the captured proteins were detected with a polyclonal CRP antibody from the BindingSite. (B) nCRP or mCRP at the indicated concentrations were added to wells (Thermo Fisher; catalog number: 442404 ) coated with 1:330 CRP-8 (clone 8) or 1:200 3H12 mAbs, and the captured proteins were detected with a polyclonal CRP antibody from the BindingSite. 
volume was used at all incubation steps, while $300-\mu \mathrm{L}$ volume was used for washing after each incubation step. Plasma samples were obtained from the First (urticaria) and Second Affiliated Hospitals (eczema and psoriasis) of Xi'an Jiaotong University. Informed consents for blood sampling were signed by all participants, and the research was in compliance with the Declaration of Helsinki and approved by the local ethical committee.

\section{Statistical Analysis}

Data were presented as mean \pm SEM. Statistical analysis was performed by one-way ANOVA, Kruskal-Wallis ANOVA or
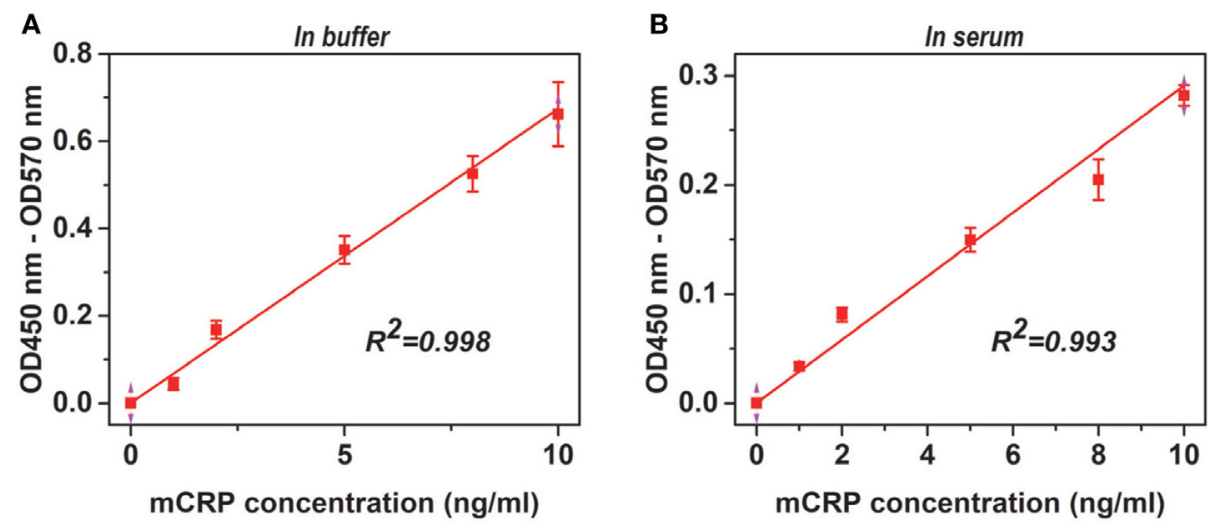

FIGURE 2 | Adaptability of the assay. Monomeric CRP (mCRP) at the indicated concentrations in TBS buffer (A) or reference human sera (1:100) (B) were added to wells (Corning) coated with 1:1,000 CRP-8 mAb (clone 8), and the captured proteins were detected with a polyclonal CRP antibody from the BindingSite. The endogenous mCRP concentrations in the reference human sera were $<10 \mathrm{ng} / \mathrm{mL}$ and therefore was undetectable following 1:100 dilution. The Pearson's correlation coefficients $(R)$ were also indicated.

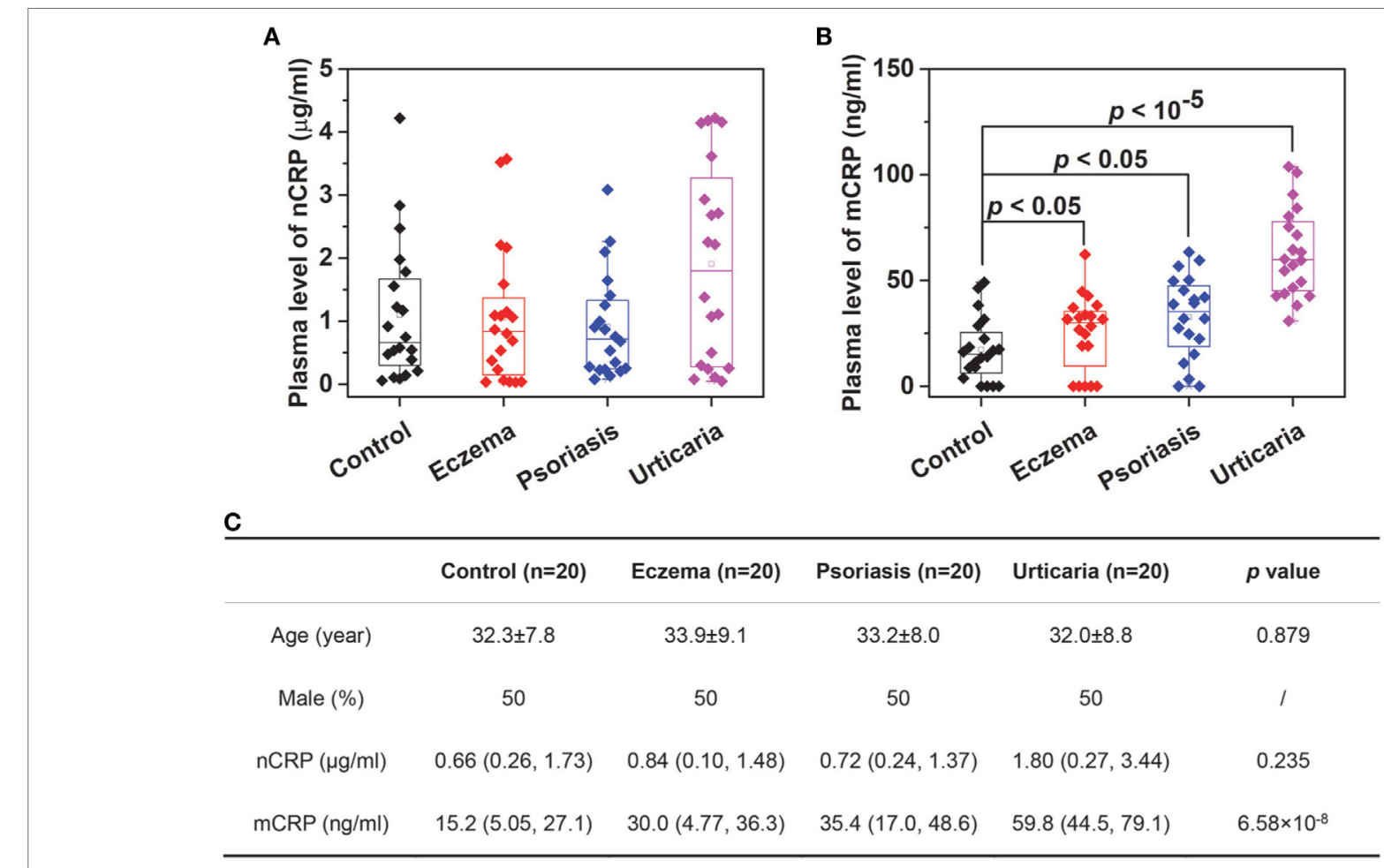

FIGURE 3 | Determination of monomeric CRP (mCRP) levels in clinical samples. The plasma levels of native C-reactive protein (nCRP) (A) and mCRP (B) were determined in healthy controls $(n=20)$ and patients with eczema $(n=20)$, psoriasis $(n=20)$, and urticaria $(n=20)$ using Corning microtiter wells coated with 1:1,000 CRP-8. (C) The summarized results. 
Kolmogorov-Smironv tests as appropriate. Differences were considered significant at values of $p<0.05$.

\section{RESULTS AND DISCUSSION}

Sandwich ELISA is a convenient yet reliable assay for laboratory quantification of antigens in clinical samples without demanding equipment requirements. In case of measuring mCRP, the key to the success is to identify an appropriate pair of capture and detection antibodies. Such an antibody pair should be highly specific and sensitive to accurately quantify low level of mCRP [probably in $\mathrm{ng} / \mathrm{mL}$ (25)] in the background of high level nCRP (usually in $\mu \mathrm{g} / \mathrm{mL}$ ). Polyclonal antibodies can bind both nCRP and mCRP, and therefore may not represent suitable candidates for being the capture antibody. Indeed, most screened pairs with polyclonal capture antibodies worked well for purified mCRP, but all failed in reconstituted mixtures or clinical samples containing both nCRP and mCRP (not shown).

For screened pairs with monoclonal capture antibodies, those using polyclonal detection antibodies performed better. A monoclonal capture antibody from Sigma (CRP-8) and a polyclonal detection antibody from BindingSite emerged as the best choice. This pair was highly selective, reaching half maximal signals for mCRP at $\sim 20 \mathrm{ng} / \mathrm{mL}$ but generating only background signals for nCRP at $1 \mu \mathrm{g} / \mathrm{mL}$ (Figure 1A). The performance of CRP-8 as the capture antibody was even superior than that of $3 \mathrm{H} 12$, an established $\mathrm{mAb}$ of $\mathrm{mCRP}$ (30) (Figure 1B). This assay could reliably report $\mathrm{mCRP}$ as low as $1 \mathrm{ng} / \mathrm{mL}$ in both purified (Figure 2A) and complex samples (Figure 2B). Its robustness was further validated by using different batches of reagents and microtiter wells, by performing in laboratories at different cities by distinct colleagues over months.

We next determined plasma levels of nCRP and mCRP in healthy controls and patients with skin-related autoimmune

\section{REFERENCES}

1. Pepys MB, Hirschfield GM. C-reactive protein: a critical update. J Clin Invest (2003) 111:1805-12. doi:10.1172/JCI200318921

2. Du Clos TW. Pentraxins: structure, function, and role in inflammation. ISRN Inflamm (2013) 2013:379040. doi:10.1155/2013/379040

3. Allin $\mathrm{KH}$, Nordestgaard BG. Elevated C-reactive protein in the diagnosis, prognosis, and cause of cancer. Crit Rev Clin Lab Sci (2011) 48:155-70. doi:10.3109/10408363.2011.599831

4. Ridker PM. From C-reactive protein to interleukin-6 to interleukin-1: moving upstream to identify novel targets for atheroprotection. Circ Res (2016) 118:145-56. doi:10.1161/CIRCRESAHA.115.306656

5. Allin KH, Nordestgaard BG, Zacho J, Tybjaerg-Hansen A, Bojesen SE. C-reactive protein and the risk of cancer: a Mendelian randomization study. J Natl Cancer Inst (2010) 102:202-6. doi:10.1093/jnci/djp459

6. Zacho J, Tybjaerg-Hansen A, Jensen JS, Grande P, Sillesen H, Nordestgaard BG. Genetically elevated C-reactive protein and ischemic vascular disease. $N$ Engl J Med (2008) 359:1897-908. doi:10.1056/NEJMoa0707402

7. Ma X, Ji SR, Wu Y. Regulated conformation changes in C-reactive protein orchestrate its role in atherogenesis. Chinese Sci Bull (2013) 58:1642-9. doi:10.1007/s11434-012-5591-3

8. Wu Y, Potempa LA, El Kebir D, Filep JG. C-reactive protein and inflammation: conformational changes affect function. Biol Chem (2015) 396:1181-97. doi:10.1515/hsz-2015-0149 disorders, including eczema, psoriasis and urticaria (Figure 3). The levels of nCRP in patients did not differ significantly from that in controls (Figure 3A), whereas the levels of mCRP were significantly higher in patients than in controls (Figure 3B). Moreover, though mCRP was increased in all three disorders, the extents of increase differed significantly with the strongest increase observed in patients with active urticaria. These results suggest that mCRP is not only more sensitive to local status of inflammation but may also be specific to the underlying pathogenesis. Therefore, large-scale investigations and thorough analysis are warranted to establish the clinical significance of mCRP in diagnosis and prognosis, and the assay developed herein provides a means for that purpose.

\section{ETHICS STATEMENT}

The study was approved by the Ethics Committee of Xian Jiaotong University. Informed consents for blood sampling were signed by all of the participants.

\section{AUTHOR CONTRIBUTIONS}

YW and S-RJ designed the research. LZ, H-YL, WL, Z-YS, and Y-DW performed the research. YW, S-RJ, LZ, and H-YL analyzed the data and wrote the paper. All authors reviewed the results and approved the final version of the manuscript.

\section{ACKNOWLEDGMENTS}

We thank the Core Facility of School of Life Sciences, Lanzhou University for technical and instrumental support. This work was supported by the National Natural Science Foundation of China (grant numbers 31470718, 31570749, and 31671339) and the Fundamental Research Funds for the Central Universities (grant numbers lzujbky-2016-k11).

9. Thiele JR, Zeller J, Bannasch H, Stark GB, Peter K, Eisenhardt SU. Targeting $\mathrm{C}$-reactive protein in inflammatory disease by preventing conformational changes. Mediators Inflamm (2015) 2015:372432. doi:10.1155/2015/372432

10. Slevin M, Krupinski J. A role for monomeric C-reactive protein in regulation of angiogenesis, endothelial cell inflammation and thrombus formation in cardiovascular/cerebrovascular disease? Histol Histopathol (2009) 24:1473-8. doi:10.14670/HH-24.1473

11. Singh SK, Suresh MV, Voleti B, Agrawal A. The connection between C-reactive protein and atherosclerosis. Ann Med (2008) 40:110-20. doi:10.1080/ 07853890701749225

12. Ji SR, Wu Y, Zhu L, Potempa LA, Sheng FL, Lu W, et al. Cell membranes and liposomes dissociate C-reactive protein (CRP) to form a new, biologically active structural intermediate: $\mathrm{mCRP}(\mathrm{m})$. FASEB J (2007) 21:284-94. doi:10.1096/fj.06-6722com

13. Eisenhardt SU, Habersberger J, Murphy A, Chen YC, Woollard KJ, Bassler N, et al. Dissociation of pentameric to monomeric C-reactive protein on activated platelets localizes inflammation to atherosclerotic plaques. Circ Res (2009) 105:128-37. doi:10.1161/CIRCRESAHA.108.190611

14. Molins B, Pena E, de la Torre R, Badimon L. Monomeric C-reactive protein is prothrombotic and dissociates from circulating pentameric $\mathrm{C}$-reactive protein on adhered activated platelets under flow. Cardiovasc Res (2011) 92:328-37. doi:10.1093/cvr/cvr226

15. de la Torre R, Pena E, Vilahur G, Slevin M, Badimon L. Monomerization of C-reactive protein requires glycoprotein IIb-IIIa activation: pentraxins 
and platelet deposition. J Thromb Haemost (2013) 11:2048-58. doi:10.1111/ jth. 12415

16. Mihlan M, Blom AM, Kupreishvili K, Lauer N, Stelzner K, Bergstrom F, et al. Monomeric C-reactive protein modulates classic complement activation on necrotic cells. FASEB J (2011) 25:4198-210. doi:10.1096/ff.11-186460

17. Lauer N, Mihlan M, Hartmann A, Schlotzer-Schrehardt U, Keilhauer C, Scholl HP, et al. Complement regulation at necrotic cell lesions is impaired by the age-related macular degeneration-associated factor- $\mathrm{H}$ His402 risk variant. J Immunol (2011) 187:4374-83. doi:10.4049/jimmunol.1002488

18. Thiele JR, Habersberger J, Braig D, Schmidt Y, Goerendt K, Maurer V, et al. Dissociation of pentameric to monomeric C-reactive protein localizes and aggravates inflammation: in vivo proof of a powerful proinflammatory mechanism and a new anti-inflammatory strategy. Circulation (2014) 130:35-50. doi:10.1161/CIRCULATIONAHA.113.007124

19. Braig D, Kaiser B, Thiele JR, Bannasch H, Peter K, Stark GB, et al. A conformational change of C-reactive protein in burn wounds unmasks its proinflammatory properties. Int Immunol (2014) 26:467-78. doi:10.1093/ intimm/dxu056

20. Habersberger J, Strang F, Scheichl A, Htun N, Bassler N, Merivirta RM, et al. Circulating microparticles generate and transport monomeric $\mathrm{C}$-reactive protein in patients with myocardial infarction. Cardiovasc Res (2012) 96:64-72. doi:10.1093/cvr/cvs237

21. Wang MS, Messersmith RE, Reed SM. Membrane curvature recognition by C-reactive protein using lipoprotein mimics. Soft Matter (2012) 8:7909-18. doi: $10.1039 / \mathrm{c} 2 \mathrm{sm} 25779 \mathrm{c}$

22. Strang F, Scheichl A, Chen YC, Wang X, Htun NM, Bassler N, et al. Amyloid plaques dissociate pentameric to monomeric C-reactive protein: a novel pathomechanism driving cortical inflammation in Alzheimer's disease? Brain Pathol (2012) 22:337-46. doi:10.1111/j.1750-3639.2011.00539.x

23. Xu PC, Lin S, Yang XW, Gu DM, Yan TK, Wei L, et al. C-reactive protein enhances activation of coagulation system and inflammatory response through dissociating into monomeric form in antineutrophil cytoplasmic antibody-associated vasculitis. BMC Immunol (2015) 16:10. doi:10.1186/s12865015-0077-0

24. Hammond DJ Jr, Singh SK, Thompson JA, Beeler BW, Rusinol AE, Pangburn MK, et al. Identification of acidic $\mathrm{pH}$-dependent ligands of pentameric C-reactive protein. J Biol Chem (2010) 285:36235-44. doi:10.1074/jbc.M110.142026

25. Wang J, Tang B, Liu X, Wu X, Wang H, Xu D, et al. Increased monomeric CRP levels in acute myocardial infarction: a possible new and specific biomarker for diagnosis and severity assessment of disease. Atherosclerosis (2015) 239:343-9. doi:10.1016/j.atherosclerosis.2015.01.024

26. Crawford JR, Trial J, Nambi V, Hoogeveen RC, Taffet GE, Entman ML. Plasma levels of endothelial microparticles bearing monomeric C-reactive protein are increased in peripheral artery disease. JCardiovasc Transl Res (2016) 9:184-93. doi:10.1007/s12265-016-9678-0

27. Potempa LA, Maldonado BA, Laurent P, Zemel ES, Gewurz H. Antigenic, electrophoretic and binding alterations of human C-reactive protein modified selectively in the absence of calcium. Mol Immunol (1983) 20:1165-75. doi:10.1016/0161-5890(83)90140-2

28. Potempa LA, Yao Z-Y, Ji S-R, Filep JG, Wu Y. Solubilization and purification of recombinant modified C-reactive protein from inclusion bodies using reversible anhydride modification. Biophy Rep (2015) 1:18-33. doi:10.1007/ s41048-015-0003-2

29. Li HY, Wang J, Meng F, Jia ZK, Su Y, Bai QF, et al. An intrinsically disordered motif mediates diverse actions of monomeric C-reactive protein. J Biol Chem (2016) 291:8795-804. doi:10.1074/jbc.M115.695023

30. Ying SC, Gewurz H, Kinoshita CM, Potempa LA, Siegel JN. Identification and partial characterization of multiple native and neoantigenic epitopes of human C-reactive protein by using monoclonal antibodies. J Immunol (1989) 143:221-8.

31. Ying SC, Shephard E, de Beer FC, Siegel JN, Harris D, Gewurz BE, et al. Localization of sequence-determined neoepitopes and neutrophil digestion fragments of C-reactive protein utilizing monoclonal antibodies and synthetic peptides. Mol Immunol (1992) 29:677-87. doi:10.1016/0161-5890 (92) $90205-\mathrm{C}$

Conflict of Interest Statement: The authors declare that the research was conducted in the absence of any commercial or financial relationships that could be construed as a potential conflict of interest.

Copyright ( 2018 Zhang, Li, Li, Shen, Wang, Ji and Wu. This is an open-access article distributed under the terms of the Creative Commons Attribution License (CC BY). The use, distribution or reproduction in other forums is permitted, provided the original author(s) and the copyright owner are credited and that the original publication in this journal is cited, in accordance with accepted academic practice. No use, distribution or reproduction is permitted which does not comply with these terms. 